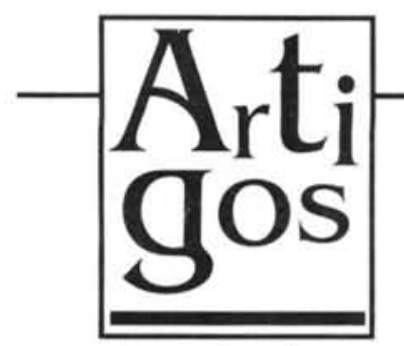

nacionais

\title{
O PODER DA
}

TELEVISÃO: RELAÇÕES ENTRE TV E POLÍTICA

\section{Em uma sociedade civil pouco organizada ganham força as imagens editadas pela mídia}

Entre as muitas mudanças que afetaram o mundo e o Brasil neste século, o surgimento dos meios de comunicação de massa, particularmente os eletrônicos (rádio e televisão), está certamente entre as mais importantes. Estas novas formas de produção massiva de bens simbólicos alteraram profundamente as relações sociais e políticas. No caso da televisão, muitos acreditam que a transformação atingiu até mesmo a natureza humana. Para o cientista político Giovanni Sartori, a televisão está transformando o homo sapiens em homo ocular, inaugurando a era da videopolíti$c a^{1}$. Ou seja, o homem da era escrita, que baseava sua visão de mundo naquilo que lia, está sendo substituído na era do videopoder por aquele que constrói esta visão a partir daquilo que vê na televisão. Vivemos hoje em dia sob o poder da imagem.

\section{O AUTOR}

\section{Mauro Pereira Porto}

Professor do Departamento de Ciência Política da Universidade de Brasília e doutorando em comunicação na Universidade da Califórnia, San Diego,EUA. E-mail: mporto@weber.ucsd.edu
Um dos campos mais interessantes para analisarmos estas mudanças provocadas pela televisão é a política. Esta é uma das esferas da atividade humana em que mais se evidencia o novo poder da televisão. Entre as várias transformações, podemos citar, por exemplo, o papel que a TV passa a ter como um novo agente do processo político, substituindo funções até então exercidas por instituições políticas tradicionais, como os partidos. $\mathrm{O}$ partido era a principal organização a desempenhar o papel de mediação entre os indivíduos e a política. Hoje, através da televisão, candidatos e forças sociais levam suas mensagens diretamente a milhões de pessoas sem necessitarem de nenhuma estrutura partidária. A TV permite que candidatos que se apresentam como outsiders, como vindos de fora do sistema, cheguem a centros geográficos antes controlados pela classe política tradicional ${ }^{2}$. Só assim podemos entender fenômenos como Collor de Mello no Brasil, Berlusconi na Itália ou Ross Perrot nos Estados Unidos, candidatos que obtiveram triunfos eleitorais ou ameaçaram partidos tradicionais prescindindo de estruturas partidárias.

Os partidos encontram-se hoje em crise em todo o mundo. São muitas as razões desta crise e não há como culpar apenas a 
televisão pelas dificuldades que estas instituições estão enfrentando. Entretanto, para muitos estudiosos, os meios de comunicação têm contribuído de forma decisiva no processo de erosão e declínio dos partidos. Para Martin Wattemberg ${ }^{3}$, um dos fatores importantes para explicar o declínio dos partidos americanos é a crescente centralização da cobertura da mídia nos candidatos e não nos partidos.

Assim, um dos impactos mais importantes da televisão é a personalização: o processo político é apresentado cada vez mais como uma disputa entre pessoas (candidatos) e não programas/ forças políticas alternativas (partidos). Em uma agenda desse tipo, existem poucos motivos para os partidos atuarem e se consolidarem.

Os candidatos, políticos e dirigentes partidários já perceberam o impacto da televisão nas antigas formas de se fazer política e começam a se adaptar aos novos tempos. Nos países com partidos mais estruturados, os próprios eventos e atividades partidárias passam a ser realizados tendo como objetivo principal o seu televisionamento. As convenções e congressos, que tradicionalmente constituíam um fórum importante de debate e deliberação interna para os membros, transformam-se cada vez mais em rituais onde se busca eliminar qualquer sinal de polêmica ou debate para apresentar a imagem de um partido unido e coeso em torno de seus candidatos, sem divisões internas. Os delegados passam então a cumprir um papel alegórico e subalterno, sem nenhuma relevância a não ser aclamar os nomes dos candidatos.
O poder da imagem impõe ainda um padrão estético necessário para o êxito dos candidatos. Não basta o candidato ter boas propostas, é preciso que ele apareça bem no vídeo. Segundo Joshua Meyrowitz ${ }^{4}$, vemos televisão em vez de ouvir televisão. Mesmo os debates políticos teriam muito pouco a ver com as palavras e argumentos, tendo muito a ver com imagem e estilo. Segundo o mesmo autor, poucas pessoas reagem a um debate político dizendo: como ele argumentou bem. A reação mais comum é do tipo: não confio nele ou ele parece nervoso. Na era da videopolítica, nossos julgamentos e escolhas sobre a política e os políticos se baseiam, de forma importante, na impressão subjetiva que suas imagens nos transmitem.

\section{A REPRESENTAÇÃO POLÍTICA}

Mas o poder da comunicação não se manifesta só nos partidos e/ou candidatos. Um aspecto fundamental é o papel da TV na construção da nossa visão da política e da sociedade, a sua relação com a audiência. Aqui é preciso dizer que a mídia não determina diretamente o que sua audiência pensa, de forma direta e simples, pois é apenas um fator que contribui para a formação da visão de mundo das pessoas. Entretanto, a televisão é certamente o elemento mais dinâmico neste processo, dada a sua posição nas sociedades contemporâneas. Em todo o mundo, a televisão aparece como a principal fonte de informação das pessoas sobre o que acontece na política. No caso brasileiro, pesquisas realizadas nacionalmente em 1989 e 1990 revelaram que entre $86 \%$ e $89 \%$ dos entrevistados declaram que tomam 


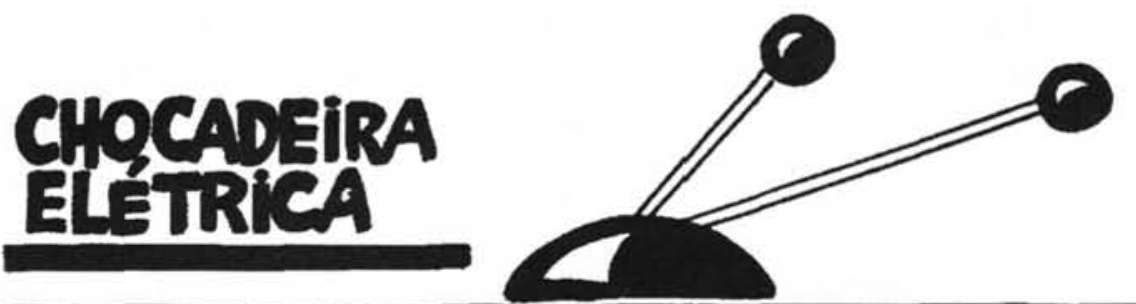

$\frac{\frac{5}{1}}{\frac{0}{3}}$

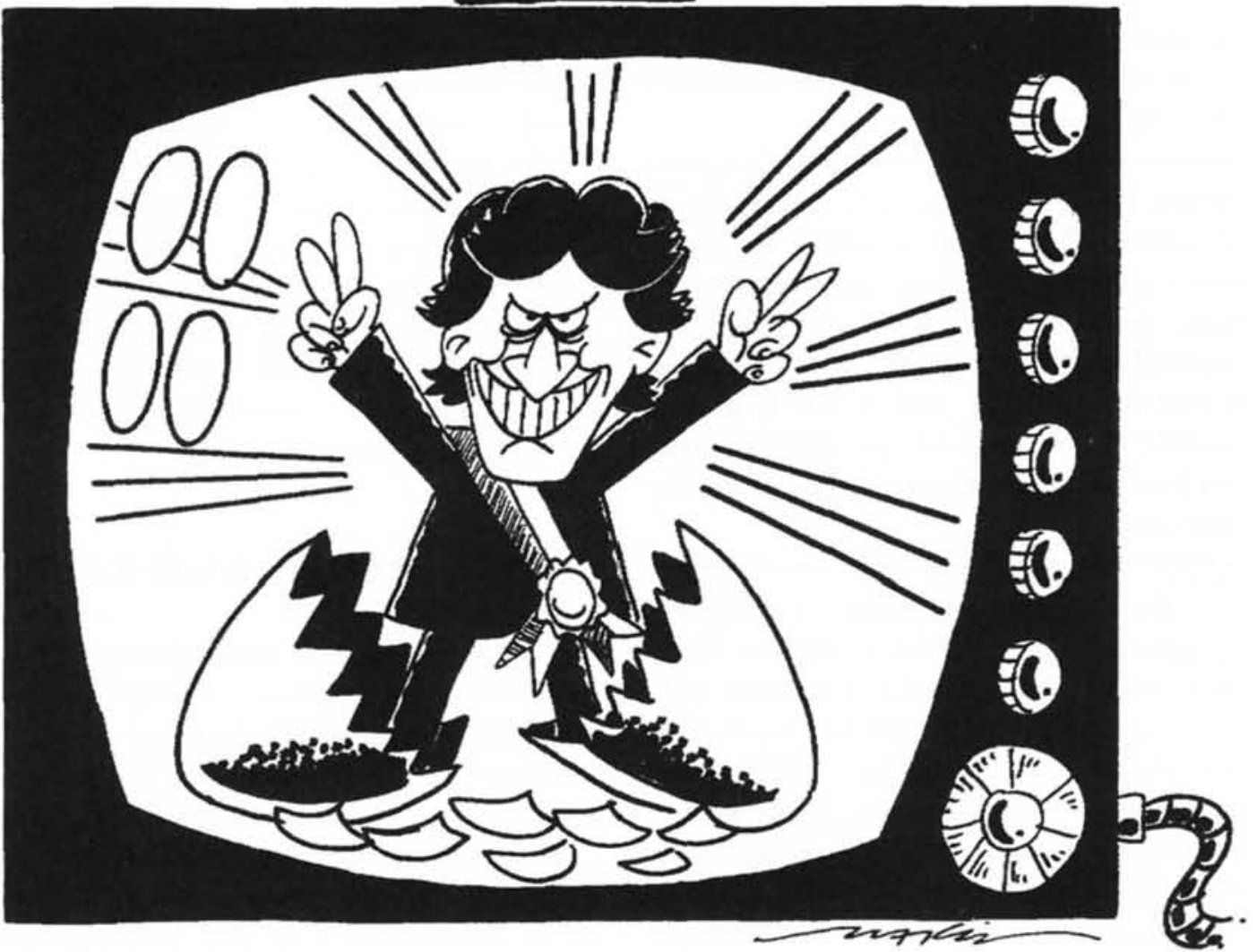

conhecimento dos acontecimentos políticos através da televisão ${ }^{5}$. Além de ser o principal meio de mediação entre os cidadãos e a política, a TV também desfruta de um alto grau de credibilidade.

A forma mais poderosa através da qual a televisão influi no processo político é a apresentação de uma visão de mundo, atra- vés da construção de representações sobre o mundo da política ${ }^{6}$. Assim, o que cada um de nós pensa sobre os partidos políticos, candidatos ou instituições como Congresso, tem relação direta, ainda que não automática ou mecânica, com as formas através das quais estes aspectos do mundo da política são representados na e pela televisão.

5. MOISÉS. José Alvaro. Democratização e cultura política de massa no Brasil. Lua Nova. n. 26. 1992.

6. Sobre a teoria das relaçôes entre midia e política a partir deste ponto de vista, consultar: LIMA. Venício A. de. Televisão e poder: a hipótese do cenário de representraçâo da política, CR-P: novos aspectos teóricos e implicações para a análise política. Comunicação \& Política, v. I, n.3, abr.jul., 1995. p. 95-106. 
Para entendermos esse papel da televisão, devemos superar a visão que tem predominado, inclusive na ciência política, que concebe os meios de comunicação como meros condutores neutros de informação. A comunicação não é um processo simples em que uma mensagem é levada de um emissor até os receptores através de um meio (televisão). É na comunicação que o significado das coisas - inclusive dos fenômenos políticos - é construído, onde o mundo da política adquire um sentido específico. A televisão não só transmite informações sobre o mundo da política: ela o interpreta, confere a ele um determinado significado.

Entender o papel da TV desta forma nos permite não só reconhecer a sua importância, mas também superar algumas teorias simplistas que tendem a ver a televisão como uma instituição onipotente, todo-poderosa, frente a uma audiência passiva, facilmente manipulável. Quando afirmo que a televisão é o elemento mais dinâmico e importante na formação da nossa visão de mundo, não pretendo afirmar que seja o único. Outras organizações da sociedade civil como partidos, igrejas, associações de bairro, sindicatos, movimentos ecológicos etc. também são importantes. Em diversos momentos históricos, quando uma determinada idéia ganhou força na sociedade civil, a televisão não conseguiu impor a sua interpretação (ou representação) da vida política e teve que retroceder. Como exemplos históricos no caso brasileiro temos a campanha pe- las eleições diretas em 1984 e a campanha pró-impeachment em 1992, quando a interpretação inicial da Rede Globo sobre ambas as campanhas teve que retroceder dado o grau de mobilização da sociedade civil ${ }^{7}$.

Entretanto, os meios de comunicação são as instituições mais importantes e dinâmicas deste processo. Este papel da televisão na construção da nossa visão sobre o mundo da política se realiza não só através dos programas explicitamente políticos, como o Horário Eleitoral Gratuito, ou ditos informativos, como o caso dos telejornais. Toda a programação da televisão está permanentemente construindo determinadas representações sobre a realidade política e social, cabendo aos programas de maior audiência um papel central.

Portanto, para entender o papel da mídia na política não basta analisar os programas explicitamente políticos ou a parte do noticiário dedicado às questões políticas, mas devemos entender inclusive o papel de programas tradicionalmente reduzidos à categoria de entretenimento, como as telenovelas. As novelas assumiram, no caso brasileiro, um papel absolutamente central na discussão de temas políticos, constituindo para muitas pessoas a principal forma de contato com o mundo da política ${ }^{8}$.

Em uma pesquisa que realizei sobre as telenovelas e a eleição presidencial de 1994 , busquei ressaltar o seu importante papel na representação de temas políticos que constituíram um cenário específico, nos marcos do qual se desenvolveu a disputa eleitoral ${ }^{9}$.

7. Sobre a campanha das diretas em 1984, ver: LIMA, Venício A. de.; RAMOS, Murilo C. A televisão no Brasil: desinformasão e democracia. In: FLEISCHER, David (org.) Da distensão à abertura: as eleições de 1982. Brasília: EdUnB, 1988, p. 215-236. Sobre o impeachment, ver: PORTO, Mauro P. As eleições municipais em São Paulo. In: MATOS, Heloísa (org.) Mídia, eleições e democracia. São Paulo: Scritta, 1994. p. 133-157.

8. PORTO. Mauro P. Telenovelas e imaginário político no Brasil. Cultura Vozes, n. 6. dezembro de 1994. p. 83-93.

9. PORTO, Mauro P. Telenovelas e política: o CR-P da eleição presidencial de 1994. Comunicação \& Política, v.I, n. 3. abr./jul., 1995. p. 55-76. 
As pessoas se informam sobre a realidade política e social não só através dos gêneros informativos, como o telejornal, mas também através de outros gêneros da programação televisiva, como é o caso das novelas.

\section{TELEVISÃO, SOCIEDADE CIVIL E DEMOCRACIA}

Reconhecer que estas mudanças na política contemporânea estão diretamente relacionadas com a televisão não significa necessariamente um diagnóstico pessimista. Não compartilho a visão, muito comum na discussão do tema, de que a televisão necessariamente despolitiza, espetaculariza, banaliza ou deturpa o debate público. Esta visão parte de uma postura saudosista sobre um suposto período idílico anterior à televisão. A televisão agrava vários dos obstáculos hoje existentes à realização de uma prática política mais genuína e democrática. Entretanto, a política sempre foi uma atividade humana complexa e dinâmica, em que práticas libertárias e excludentes estiveram presentes. E não existem motivos para se acreditar que a televisão não possa contri-

Resumo: O artigo destaca o papel da mídia, principalmente da TV, como um novo agente do processo politico, substituindo até instituiçōes tradicionais como os Partidos. Analisa como essa força atua no vácuo de uma sociedade civil pouco organizada, na qual prepondera um sistema de comunicação anti-democrático.

Palavras-chave: mídia, televisão, política, democracia buir para o estabelecimento de práticas libertárias no mundo de hoje.

A capacidade de a TV colaborar para o estabelecimento de um processo político democrático e plural depende, todavia, da organização da sociedade civil e da democratização do próprio sistema de comunicação.

O poder da comunicação levanta questões muito importantes sobre a democracia, principalmente em uma sociedade como a brasileira, na qual os meios de comunicação se desenvolveram em um ambiente de pouca regulamentação legal e pública. Além disso, somos um dos poucos países do mundo em que uma única rede de televisão constitui um virtual monopólio de audiência. A saída não passa certamente pelo estabelecimento de censura ou controle burocrático por parte do Estado. Entretanto, se pretendemos consolidar a democracia brasileira, certamente teremos que pensar formas para aproximar a mídia da sociedade civil, buscando uma máxima e factível publicização dos sistemas de comunicação.

Abstract: This paper points out the role played by media, mainly by television, as a new agent in the political process, even acting as a substitute for traditional institutions such as political parties. It analyses in what way this force takes action in the vacuum of a poorly organized civil society in which an anti-democratic communication system prevails.

Key-words: media, television, politics, democracy 